\title{
Association between the neutrophil-to-lymphocyte ratio, a new marker of systemic inflammation, and restless legs syndrome
}

Ceyhun Varım${ }^{1}$, MD, Bilgehan Atılgan $\underline{A c a r}^{2}$, MD, Mehmet Sevki Uyanık ${ }^{3}$, MD, Turkan Acar ${ }^{2}$, MD, Neslihan Alagoz ${ }^{2}$,MD, Ahmet Nalbant ${ }^{1}, \mathrm{MD}$, Tezcan Kaya ${ }^{1}$, MD, Hasan Ergenc $^{1}$, MD

\begin{abstract}
INTRODUCTION Restless legs syndrome (RLS), also known as Willis-Ekbom disease, is characterised by abnormal sensations in the legs as well as dysaesthesia. Although the aetiology of RLS has not yet been determined, it may be associated with systemic inflammation. The neutrophil-to-lymphocyte ratio (NLR) is a new and simple marker indicating systemic inflammation. The present study aimed to investigate the relationship between systemic inflammation and RLS through the use of the NLR.

METHODS A total of 75 newly diagnosed patients with RLS and 56 healthy control subjects were included in the study. Baseline NLR was calculated by dividing the absolute neutrophil count by the absolute lymphocyte count. The NLRs of the two groups were compared.

RESULTS There were no significant differences in gender and age between the two groups. The NLR was $1.96 \pm 0.66$ in the patient group and $1.67 \pm 0.68$ in the control group $(p=0.005)$. Receiver operating characteristic analysis was performed to determine the cut-off value of NLR to predict RLS. The NLR was predictive at 1.58 with a $64 \%$ sensitivity and $50 \%$ specificity ( $95 \%$ confidence interval $0.55-0.74$, area under curve $0.648 \pm 0.05$ ). The NLR was found to be statistically higher in patients with RLS and may be used to predict RLS.

CONCLUSION The aetiology of RLS remains undetermined. The present study showed that systemic inflammation may play a role in RLS. However, RLS could also be associated with systemic inflammatory diseases. This relationship is supported by high NLR values, which are related to chronic systemic inflammation.
\end{abstract}

Keywords: neutrophil-to-lymphocyte ratio, restless legs syndrome, systemic inflammation

\section{INTRODUCTION}

Restless legs syndrome (RLS) is a sensory-motor neurological disorder in which the main symptoms are an urge to move the legs, abnormal sensations in the legs and dysaesthesia at rest. These symptoms worsen at night, affecting sleep quality. ${ }^{(1)}$ RLS, also known as Willis-Ekbom disease, was first described in 1945 by Dr Karl Ekbom ${ }^{(2)}$, although its aetiology was not determined until recently. The most common theory in the aetiology of RLS is dopaminergic dysfunction. RLS can be categorised as idiopathic or secondary. Secondary RLS occurs due to disease or conditions such as iron deficiency, chronic renal failure or pregnancy. ${ }^{(3)}$ Previous studies have also associated it with systemic inflammatory diseases ${ }^{(4-7)}$ and small intestinal bacterial overgrowth. ${ }^{(8)}$ Hence, RLS may be related to inflammatory status.

The neutrophil-to-lymphocyte ratio (NLR) has recently begun to be used as a marker of systemic inflammation. Compared to other inflammation markers, the NLR is simpler and less costly to measure. Studies have shown a relationship between NLR, coronary artery disease, ${ }^{(9)}$ heart failure, ${ }^{(10)}$ diabetes mellitus ${ }^{(11)}$ and other malignancies. ${ }^{(12,13)}$ In this study, we aimed to assess the relationship between RLS and systemic inflammation via the use of NLR values. To the best of our knowledge, there are no prior studies on this subject.

\section{METHODS}

Newly diagnosed patients with RLS and healthy control subjects were recruited for this study. RLS was diagnosed using the International Restless Legs Syndrome Study Group questionnaire, which consists of four questions: (a) Do you have an urge to move your legs, accompanied by uncomfortable or disagreeable feelings?; (b) Do the uncomfortable or disagreeable feelings begin or worsen during inactive periods?; (c) Are the uncomfortable or disagreeable feelings reduced by activity?; and (d) Are the uncomfortable or disagreeable feelings more prominent in the evening or at bedtime? Patients who answered 'yes' to all questions were diagnosed with RLS. Those who were excluded had polyneuropathy, lumbosacral radiculopathy, amyotrophic lateral sclerosis, myeloma, multiple sclerosis, Parkinson's disease, poliomyelitis, diabetes mellitus, uraemia, amyloidosis, gastrectomy, cancer, chronic obstructive pulmonary disease, peripheral vascular disease, congestive heart failure, Cushing's syndrome, hypo- or hyperthyroidism, pregnancy, lactation, chronic renal failure, chronic liver disease, usage of neuroleptics or antidepressants, steroid therapy (due to any reason), systemic inflammatory diseases (systemic lupus erythematosus, rheumatoid arthritis), previous history of smoking, or haematological diseases. The study protocol was approved by the institutional ethics committee. 
After 12-14 hours of fasting, venous blood samples were obtained from the patients for biochemical and haemogram studies. Complete blood cell count and automated differential count were determined using an automated haematology analyser, the Abbott CELL-DYN 3700 System (Abbott Laboratories, Abbott Park, IL, USA), which provided total white blood cell, platelet, neutrophil, lymphocyte, monocyte, eosinophil and basophils counts per microlitre. The NLR was calculated by dividing the absolute neutrophil count by the absolute lymphocyte count.

SPSS Statistics version 17.0 (SPSS Inc, Chicago, IL, USA) was used to perform statistical analysis. Normality was assessed with Kolmogorov-Smirnov test. Mean differences were calculated with $t$-test for continuous variables and chi-square test was used to assess differences between non-continuous variables. Receiver operating characteristic (ROC) curves were used when appropriate. A p-value $<0.05$ indicated statistical significance.

\section{RESULTS}

A total of 131 patients were included in the data analysis. There were 75 newly diagnosed patients with RLS (i.e. RLS group) and 56 healthy subjects (i.e. control group). The groups were determined to be homogenous in terms of demographic characteristics and body mass index. There were no significant gender and age differences between the two groups (Table I).

Haemogram and anaemia parameters of the RLS and control groups are shown in Table II. Neutrophil counts were higher in

Table I. Demographic characteristics of the patients $(n=131)$.

\begin{tabular}{lccc}
\hline Parameter & \multicolumn{2}{c}{ No. (\%) } & p-value \\
\cline { 2 - 3 } & $\begin{array}{c}\text { RLS group } \\
(\mathbf{n}=\mathbf{7 5})\end{array}$ & $\begin{array}{c}\text { Control group } \\
(\mathbf{n}=\mathbf{5 6})\end{array}$ & \\
\hline Gender & $16(21.3)$ & $19(33.9)$ & 0.108 \\
Male & $59(78.7)$ & $37(66.1)$ & \\
Female & $45.6 \pm 9.4$ & $48.1 \pm 11.4$ & 0.184 \\
Age* $^{(\mathbf{y r})}$ & $28.9 \pm 5.9$ & $28.3 \pm 5.3$ & 0.499 \\
BMI* $^{\left(\mathbf{k g} / \mathbf{m}^{2}\right)}$ & & & \\
\hline
\end{tabular}

*Data presented as mean \pm standard deviation. BMI: body mass index; RLS: restless legs syndrome the RLS group compared to the control group $(4.0 \pm 1.2 \mathrm{~K} / \mu \mathrm{L}$ vs. $3.4 \pm 1.3 \mathrm{~K} / \mu \mathrm{L} ; \mathrm{p}=0.003)$; the NLR was also significantly higher at $1.96 \pm 0.66$ in the RLS group and $1.67 \pm 0.68$ in the control group ( $p=0.005)$. ROC analysis was performed to determine the cut-off value of the NLR to predict RLS. The NLR was predictive at 1.58 with a $64 \%$ sensitivity and $50 \%$ specificity $(95 \%$ confidence interval 0.55-0.74, area under curve $0.648 \pm 0.05$ ) (Fig. 1).

In summary, neutrophil counts and the NLR were significantly higher in the patients with RLS. Vitamin B12, ferritin, and folate levels were found to be significantly lower; however, they were within the normal range.

\section{DISCUSSION}

The NLR was found to be higher in patients with RLS, supporting the idea that systemic inflammation plays a role in RLS aetiology or that RLS is related to systemic inflammatory diseases. To the best of our knowledge, our study is the first to show the relationship between NLR and RLS.

Dopamine imbalance and iron deficiency are the most common theories of RLS aetiology. ${ }^{(14-16)}$ Although several studies can be found in the literature on this subject, the relationship between systemic inflammation and RLS has been studied only in recent years. Weinstock et al found a higher prevalence of irritable bowel syndrome and small intestinal bacterial overgrowth in patients with RLS. ${ }^{(8)}$ Other inflammatory diseases have been

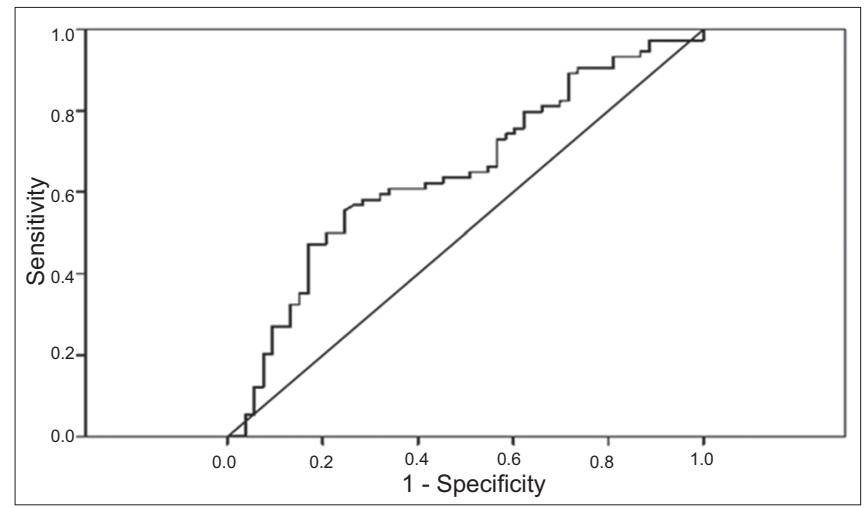

Fig. 1 Graph shows the receiver operating characteristic curve for neutrophil-to-lymphocyte ratio in predicting restless legs syndrome.

Table II. Haematological parameters of patients in the two groups $(n=131)$.

\begin{tabular}{|c|c|c|c|c|}
\hline \multirow[t]{2}{*}{ Parameter } & \multicolumn{2}{|c|}{ Mean \pm standard deviation } & \multirow[t]{2}{*}{ Normal range } & \multirow[t]{2}{*}{ p-value } \\
\hline & RLS group $(n=75)$ & Control group $(n=56)$ & & \\
\hline Haemoglobin (g/dL) & $13.1 \pm 1.4$ & $13.4 \pm 2.1$ & $12.2-18.1$ & 0.28 \\
\hline Haematocrit (\%) & $38.7 \pm 4.0$ & $39.4 \pm 5.6$ & $37.7-53.7$ & 0.5 \\
\hline White blood cell $(\mathrm{K} / \mu \mathrm{L})$ & $6.8 \pm 1.6$ & $6.3 \pm 2.0$ & $4.6-10.2$ & 0.69 \\
\hline Neutrophil $(K / \mu \mathrm{L})$ & $4.0 \pm 1.2$ & $3.4 \pm 1.3$ & $2.0-6.9$ & 0.003 \\
\hline Lymphocyte $(\mathrm{K} / \mu \mathrm{L})$ & $2.1 \pm 0.6$ & $2.2 \pm 0.8$ & $0.6-3.4$ & 0.85 \\
\hline Platelet $(\mathrm{K} / \mu \mathrm{L})$ & $292 \pm 78$ & $284 \pm 64$ & $142-424$ & 0.71 \\
\hline NLR & $1.96 \pm 0.66$ & $1.67 \pm 0.68$ & - & 0.005 \\
\hline Ferritin $(\mathrm{ng} / \mathrm{mL})$ & $37.9 \pm 32.9$ & $54.3 \pm 41.4$ & $30-400$ & 0.018 \\
\hline Folate (ng/mL) & $6.5 \pm 2.7$ & $9.7 \pm 12.1$ & $4.5-32.2$ & 0.012 \\
\hline Vitamin B12 (pg/mL) & $275 \pm 135$ & $382 \pm 295$ & $191-663$ & $<0.001$ \\
\hline
\end{tabular}

NLR: neutrophil-to-lymphocyte ratio; RLS: restless legs syndrome 
associated with RLS as well. In a study by Hassan et al, RLS was found to be more prevalent in women with systemic lupus erythematosus; obesity was also found to be a significant risk factor for RLS. ${ }^{(4)}$ Another study showed that RLS had common comorbidities with rheumatoid arthritis. ${ }^{(17)}$ All of these diseases associated with RLS have immunological and inflammatory mechanisms.

Hypoxia-inducible factor-1 alpha (HIF-1a) plays a role in inflammation as a regulator. ${ }^{(18)}$ Patten et al found high HIF-1a levels in the substantia nigra neurons in patients with RLS, ${ }^{(19)}$ which shows the role of inflammation in RLS at the cellular level. In addition, patients infected by the human immunodeficiency virus showed a significantly higher prevalence rate for RLS than the general population. ${ }^{(4)}$ RLS has also been observed as a neurological complication of hepatitis $\mathrm{C}$, another chronic inflammatory disease. ${ }^{(4)}$ Matsuo et al found an association between RLS and streptococcal or mycoplasma infections in three different children. ${ }^{(20)} \mathrm{A}$ case report in the literature showed that RLS occurred after myelitis in a patient with Lyme disease. ${ }^{(21)}$

The NLR, a new and inexpensive marker, provides a simple method to assess inflammatory status. High NLR values were found in cases of acute or chronic inflammation, such as acute pancreatitis, ${ }^{(22)}$ chronic tonsillitis, ${ }^{(23)}$ acute mesenteric ischaemia, ${ }^{(24)}$ coronary artery disease, ${ }^{(9)}$ heart failure, ${ }^{(10)}$ diabetes mellitus ${ }^{(11)}$ and other malignancies. ${ }^{(12,13)}$ However, some limitations of our study should be noted. Firstly, many factors can affect the neutrophil and lymphocyte count. Hence, a detailed anamnesis must be taken. Second, the sample size was small. More multi-centre studies with a larger population need to be conducted on this subject in the future.

In conclusion, RLS should be seen as a disorder associated with inflammation. If secondary RLS is suspected, further laboratory tests and imaging methods can be performed to exclude inflammatory and autoimmune diseases.

\section{REFERENCES}

1. Allen RP, Picchietti D, Hening WA, et al; Restless Legs Syndrome Diagnosis and Epidemiology workshop at the National Institutes of Health; International Restless Legs Syndrome Study Group. Restless legs syndrome: diagnostic criteria, special considerations, and epidemiology. A report from the restless legs syndrome diagnosis and epidemiology workshop at the National Institutes of Health. Sleep Med 2003; 4:101-19.

2. Ekbom K. Restless legs: a clinical study. Acta Med Scand Suppl 1945; 158:1-123.

3. Tarsy D, Silber MH. Treatment of restless legs syndrome/Willis-Ekbom disease and periodic limb movement disorder in adults. In: UpToDate [online]. Available at: http://www.uptodate.com/contents/treatmentof-restless-legs-syndrome-willis-ekbom-disease-and-periodic-limbmovement-disorder-in-adults. Accessed May 31, 2016.

4. Hassan N, Pineau CA, Clarke AE, et al. Systemic lupus and risk of restless legs syndrome. J Rheumatol 2011; 38:874-6.

5. Happe S, Kundmüller L, Reichelt D, Husstedt IW, Evers S. Comorbidity of restless legs syndrome and HIV infection. J Neurol 2007; 254:1401-6.

6. Weinstock LB, Bosworth BP, Scherl EJ, et al. Crohn's disease is associated with restless legs syndrome. Inflamm Bowel Dis 2010; 16:275-9.

7. Weinstock LB, Walters AS, Mullin GE, Duntley SP. Celiac disease is associated with restless legs syndrome. Dig Dis Sci 2010; 55:1667-73.

8. Weinstock LB, Walters AS. Restless legs syndrome is associated with irritable bowel syndrome and small intestinal bacterial overgrowth. Sleep Med 2011; 12:610-3.

9. Kaya H, Ertaş F, İslamoğlu $Y$, et al. Association between neutrophil to lymphocyte ratio and severity of coronary artery disease. Clin Appl Thromb Hemost. 2014; 20:50-4.

10. Uthamalingam S, Patvardhan EA, Subramanian S, et al. Utility of the neutrophil to lymphocyte ratio in predicting long-term outcomes in acute decompensated heart failure. Am J Cardiol 2011; 107:433-8.

11. Lou M, Luo P, Tang R, et al. Relationship between neutrophil-lymphocyte ratio and insulin resistance in newly diagnosed type 2 diabetes mellitus patients. BMC Endocr Disord 2015; 15:9.

12. Cho H, Hur HW, Kim SW, et al. Pre-treatment neutrophil to lymphocyte ratio is elevated in epithelial ovarian cancer and predicts survival after treatment. Cancer Immunol Immunother 2009; 58:15-23.

13. Yamanaka T, Matsumoto S, Teramukai $S$, et al. The baseline ratio of neutrophils to lymphocytes is associated with patient prognosis in advanced gastric cancer. Oncology 2007; 73:215-20.

14. Allen R. Dopamine and iron in the pathophysiology of restless legs syndrome (RLS). Sleep Med 2004; 5:385-91.

15. Trenkwalder C, Högl B, Benes H, Kohnen R. Augmentation in restless legs syndrome is associated with low ferritin. Sleep Med 2008; 9:572-4.

16. Bjorvatn B, Leissner L, Ulfberg J, et al. Prevalence, severity and risk factors of restless legs syndrome in the general adult population in two Scandinavian countries. Sleep Med 2005; 6:307-12.

17. Gjevre JA, Taylor Gjevre RM. Restless legs syndrome as a comorbidity in rheumatoid arthritis. Autoimmune Dis 2013; 2013:352782.

18. Imtiyaz HZ, Simon MC. Hypoxia-inducible factors as essential regulators of inflammation. Curr Top Microbiol Immunol 2010; 345:105-20.

19. Patton SM, Ponnuru P, Snyder AM, Podskalny GD, Connor JR. Hypoxiainducible factor pathway activation in restless legs syndrome patients. Eur J Neurol 2011; 18:1329-35.

20. Matsuo M, Tsuchiya K, Hamasaki Y, Singer HS. Restless legs syndrome: association with streptococcal or mycoplasma infection. Pediatr Neurol 2004; 31:119-21.

21. Hemmer B, Riemann D, Glocker FX, Lücking CH, Deuschl G. Restless legs syndrome after a borrelia-induced myelitis. Move Disord 1995; 10:521-2.

22. Suppiah A, Malde D, Arab T, et al. The prognostic value of the neutrophillymphocyte ratio (NLR) in acute pancreatitis: identification of an optimal NLR. J Gastrointest Surg 2013; 17:675-81.

23. Yenigun A. The efficacy of tonsillectomy in chronic tonsillitis patients as demonstrated by the neutrophil-to-lymphocyte ratio. J Laryngol Otol 2015; 129:386-91

24. Aktimur R, Cetinkunar S, Yildirim K, et al. Neutrophil-to-lymphocyte ratio as a diagnostic biomarker for the diagnosis of acute mesenteric ischemia. Eur J Trauma Emerg Surg 2016; 42:363-8. 